\title{
Strong convergence of a parallel iterative algorithm in a reflexive Banach space
}

\author{
Yuan Qing ${ }^{1}$ and Songtao LV ${ }^{2 *}$
}

\author{
"Correspondence: sqlvst@yeah.net \\ ${ }^{2}$ School of Mathematics and \\ Information Science, Shangqiu \\ Normal University, Shangqiu, \\ Henan, China \\ Full list of author information is \\ available at the end of the article
}

\begin{abstract}
In this paper, a parallel iterative algorithm is investigated for common zeros of a family of $m$-accretive operators. Strong convergence theorems are established in a reflexive Banach space.
\end{abstract}

MSC: $47 \mathrm{H06}$; 47H09

Keywords: accretive operator; resolvent; nonexpansive mapping; proximal point algorithm; zero

\section{Introduction}

In this paper, we are concerned with the problem of finding common zero points of a finite family of accretive operators in a reflexive Banach space. Many nonlinear problems arising in applied areas such as image recovery and signal processing are mathematically modeled as fixed or zero point problems. Interest in accretive operators stems mainly from their firm connection with equations of evolution is an important class of nonlinear operators. It is well known that many physically significant problems can be modeled by initial value problems (IVP) of the following form:

$$
x^{\prime}(t)+A x(t)=0, \quad x(0)=x_{0},
$$

where $A$ is an accretive operator in an appropriate Banach space. Typical examples where such evolution equations occur can be found in the heat, wave or Schrödinger equations. If $x(t)$ is dependent on $t$, then (1.1) is reduced to $A u=0$ whose solutions correspond to the equilibrium points of (1.1). An early fundamental result in the theory of accretive operators, due to Browder [1], states that IVP (1.1) is solvable if $A$ is locally Lipschitz and accretive on $E$. One of the most popular techniques for solving zero points of accretive operators is the proximal point algorithms, which have been studied by many authors; see [2-27] and the references therein.

In this paper, we propose a viscosity proximal point algorithm for treating common zeros of a finite family of accretive operators. Strong convergence of the algorithm is obtained in the framework of reflexive Banach spaces.

Let $E$ be a Banach space with the dual $E^{*}$. Let $R^{+}$be the positive real number set. Let $\varphi:[0, \infty]:=R^{+} \rightarrow R^{+}$be a continuous strictly increasing function such that $\varphi(0)=0$ and $\varphi(t) \rightarrow \infty$ as $t \rightarrow \infty$. This function $\varphi$ is called a gauge function. The duality mapping

( 2014 Qing and Lv; licensee Springer. This is an Open Access article distributed under the terms of the Creative Commons Attribution License (http://creativecommons.org/licenses/by/2.0), which permits unrestricted use, distribution, and reproduction in any medium, provided the original work is properly cited. 
$J_{\varphi}: E \rightarrow E^{*}$ associated with a gauge function $\varphi$ is defined by

$$
J_{\varphi}(x)=\left\{f^{*} \in E^{*}:\left\langle x, f^{*}\right\rangle=\|x\| \varphi(\|x\|),\left\|f^{*}\right\|=\varphi(\|x\|)\right\}, \quad \forall x \in E,
$$

where $\langle\cdot, \cdot\rangle$ denotes the generalized duality pairing. In the case that $\varphi(t)=t$, we write $J$ for $J_{\varphi}$ and call $J$ the normalized duality mapping.

Following Browder [28], we say that a Banach space $E$ has a weakly continuous duality mapping if there exists a gauge $\varphi$ for which the duality mapping $J_{\varphi}(x)$ is single valued and weak-to-weak* sequentially continuous (i.e., if $\left\{x_{n}\right\}$ is a sequence in $E$ weakly convergent to a point $x$, then the sequence $J_{\varphi}\left(x_{n}\right)$ converges weakly* to $\left.J_{\varphi}\right)$. It is well known that $l^{p}$ has a weakly continuous duality mapping with a gauge function $\varphi(t)=t^{p-1}$ for all $1<p<\infty$. Set

$$
\Phi(t)=\int_{0}^{t} \varphi(\tau) d \tau, \quad \forall t \geq 0
$$

then

$$
J_{\varphi}(x)=\partial \Phi(\|x\|), \quad \forall x \in E,
$$

where $\partial$ denotes the subdifferential in the sense of convex analysis.

A Banach space $E$ is said to be strictly convex if and only if

$$
\|x\|=\|y\|=\|(1-\lambda) x+\lambda y\|
$$

for $x, y \in E$ and $0<\lambda<1$ implies that $x=y$.

$E$ is said to be uniformly convex if for any $\epsilon \in(0,2]$ there exists $\delta>0$ such that for any $x, y \in U_{E}$,

$$
\|x-y\| \geq \epsilon \quad \text { implies } \quad\left\|\frac{x+y}{2}\right\| \leq 1-\delta .
$$

It is well known that a uniformly convex Banach space is reflexive and strictly convex.

Let $U_{E}=\{x \in E:\|x\|=1\}$. $E$ is said to be smooth or said to be have a Gâteaux differentiable norm if the $\operatorname{limit}_{t \rightarrow 0} \frac{\|x+t y\|-\|x\|}{t}$ exists for each $x, y \in U_{E}$. $E$ is said to have a uniformly Gâteaux differentiable norm if for each $y \in U_{E}$, the limit is attained uniformly for all $x \in U_{E}$. $E$ is said to be uniformly smooth or said to have a uniformly Fréchet differentiable norm if the limit is attained uniformly for $x, y \in U_{E}$.

It is well known that Fréchet differentiability of the norm of $E$ implies Gâteaux differentiability of the norm of $E$. It is well known that if the norm of $E$ is uniformly Gâteaux differentiable, then the duality mapping $J$ is single valued and uniformly norm to weak* continuous on each bounded subset of $E$.

Let $I$ denote the identity operator on $E$. An operator $A \subset E \times E$ with domain $D(A)=\{z \in$ $E: A z \neq \emptyset\}$ and range $R(A)=\bigcup\{A z: z \in D(A)\}$ is said to be accretive if for each $x_{i} \in D(A)$ and $y_{i} \in A x_{i}, i=1,2$, there exists $j\left(x_{1}-x_{2}\right) \in J\left(x_{1}-x_{2}\right)$ such that $\left\langle y_{1}-y_{2}, j\left(x_{1}-x_{2}\right)\right\rangle \geq 0$. An accretive operator $A$ is said to be $m$-accretive if $R(I+r A)=E$ for all $r>0$. In this paper, we use $A^{-1}(0)$ to denote the set of zero points of $A$. For an accretive operator $A$, we can 
define a single-valued mapping $J_{r}: R(I+r A) \rightarrow D(A)$ by $J_{r}=(I+r A)^{-1}$ for each $r>0$, which is called the resolvent of $A$.

Let $C$ be a nonempty closed convex subset of $E$. Let $T: C \rightarrow C$ be a mapping. In this paper, we use $F(T)$ to denote the set of fixed points of $T$. Recall that $T$ is said to be $\alpha$-contractive iff there exists a constant $\alpha \in[0,1)$ such that $\|T x-T y\| \leq \alpha\|x-y\|, \forall x, y \in C$. $T$ is said to be nonexpansive iff $\|T x-T y\| \leq\|x-y\|, \forall x, y \in C$. It is well known that many nonlinear problems can be reduced to the search for fixed points of nonexpansive mappings; see [29-35] and the references therein. Iterative methods are often used for finding and approximating such fixed points.

Let $x$ be a fixed element in $C$ and let $T$ be a nonexpansive mapping with a nonempty fixed point set. For each $t \in(0,1)$, let $x_{t}$ be the unique solution of the equation $y=t x+(1-$ $t) T y$. In the framework of reflexive Banach spaces, Qin et al. [15] recently proved that $\left\{x_{t}\right\}$ converges strongly to a fixed point of $T$ as $t \rightarrow 0$; see [15] and the references therein.

In this paper, we propose a parallel iterative algorithm for treating common zeros of a family of $m$-accretive operators. Strong convergence theorems are established in a reflexive Banach space.

Lemma 1.1 [36] Let $\left\{x_{n}\right\}$ and $\left\{y_{n}\right\}$ be bounded sequences in a Banach space $E$ and let $\beta_{n}$ be a sequence in $[0,1]$ with $0<\liminf _{n \rightarrow \infty} \beta_{n} \leq \limsup _{n \rightarrow \infty} \beta_{n}<1$. Suppose that $x_{n+1}=$ $\left(1-\beta_{n}\right) y_{n}+\beta_{n} x_{n}$ for all $n \geq 0$ and

$$
\limsup _{n \rightarrow \infty}\left(\left\|y_{n+1}-y_{n}\right\|-\left\|x_{n+1}-x_{n}\right\|\right) \leq 0 .
$$

Then $\lim _{n \rightarrow \infty}\left\|y_{n}-x_{n}\right\|=0$.

Lemma 1.2 [37] Let $C$ be a closed convex subset of a strictly convex Banach space E. Let $N \geq 1$ be some positive integer and let $T_{m}: C \rightarrow C$ be a nonexpansive mapping. Let $\left\{\delta_{m}\right\}$ be a real number sequence in $(0,1)$ such that $\sum_{m=1}^{N} \delta_{m}=1$. Suppose that $\bigcap_{m=1}^{N} F\left(T_{m}\right)$ is nonempty. Then the mapping $\sum_{m=1}^{N} \delta_{m} T_{m}$ is nonexpansive with $F\left(\sum_{m=1}^{N} \delta_{m} T_{m}\right)=$ $\bigcap_{m=1}^{N} F\left(T_{m}\right)$.

The following lemma can be obtained from [38] immediately.

Lemma 1.3 Let $E$ be a reflexive Banach space and has a weakly continuous duality map $J_{\varphi}(x)$ with gauge $\varphi$. Let $C$ be nonempty closed convex subset of $E$. Let $f: C \rightarrow C$ be an $\alpha$ contractive mapping and let $T: C \rightarrow C$ be a nonexpansive mapping. Let $x_{t} \in C$ be the unique fixed point of the mapping $t f+(1-t) T$, where $t \in(0,1)$. Then $T$ has a fixed point if and only if $\left\{x_{t}\right\}$ remains bounded as $t \rightarrow 0^{+}$, and in this case, $\left\{x_{t}\right\}$ converges as $t \rightarrow 0^{+}$ strongly to a fixed point $\bar{x}$ of $T$, where $\bar{x}$ is the unique solution to the following variational inequality: $\left\langle f(\bar{x})-\bar{x}, J_{\varphi}(p-\bar{x})\right\rangle \leq 0, \forall p \in \bigcap_{m=1}^{N} A_{m}^{-1}(0)$.

The first part of the next lemma is an immediate consequence of the subdifferential inequality and the proof of the second part can be found in [39].

Lemma 1.4 Assume that a Banach space $E$ has a weakly continuous duality mapping $J_{\varphi}$ with a gauge $\varphi$. 
(i) For all $x, y \in E$, the following inequality holds:

$$
\Phi(\|x+y\|) \leq \Phi(\|x\|)+\left\langle y, J_{\varphi}(x+y)\right\rangle .
$$

In particular, for all $x, y \in E$,

$$
\|x+y\|^{2} \leq\|x\|^{2}+2\langle y, J(x+y)\rangle
$$

(ii) Assume that a sequence $\left\{x_{n}\right\}$ in $E$ converges weakly to a point $x \in E$.

Then the following identity holds:

$$
\limsup _{n \rightarrow \infty} \Phi\left(\left\|x_{n}-y\right\|\right)=\limsup _{n \rightarrow \infty} \Phi\left(\left\|x_{n}-x\right\|\right)+\Phi(\|y-x\|), \quad \forall x, y \in E .
$$

Lemma 1.5 [40] Let $\left\{a_{n}\right\},\left\{b_{n}\right\}$ and $\left\{c_{n}\right\}$ be three nonnegative real sequences satisfying $b_{n+1} \leq\left(1-a_{n}\right) b_{n}+a_{n} c_{n}, \forall n \geq n_{0}$, where $n_{0}$ is some positive integer, $\left\{a_{n}\right\}$ is a number sequence in $(0,1)$ such that $\sum_{n=n_{0}}^{\infty} a_{n}=\infty,\left\{c_{n}\right\}$ is a number sequence such that $\lim _{\sup _{n \rightarrow \infty}} c_{n} \leq 0$. Then $\lim _{n \rightarrow \infty} a_{n}=0$.

\section{Main results}

Theorem 2.1 Let $E$ be a strictly convex and reflexive Banach space which has a weakly continuous duality map $J_{\varphi}$. Let $N \geq 1$ be some positive integer and let $A_{i}$ be an m-accretive operator in E for each $i \in\{1,2, \ldots, N\}$. Assume that $\bigcap_{i=1}^{N} \overline{D\left(A_{i}\right)}$ is convex and $\bigcap_{i=1}^{N} A_{i}^{-1}(0)$ is not empty. Let $\left\{\alpha_{n}\right\},\left\{\beta_{n}\right\},\left\{\gamma_{n}\right\}$, and $\left\{\delta_{n, i}\right\}$ be real number sequences in $(0,1)$. Let $\left\{x_{n}\right\}$ be a sequence in $\bigcap_{i=1}^{N} \overline{D\left(A_{i}\right)}$ generated in the following iterative process: $x_{1} \in \bigcap_{i=1}^{N} \overline{D\left(A_{i}\right)}$ and

$$
x_{n+1}=\alpha_{n} f\left(x_{n}\right)+\beta_{n} x_{n}+\gamma_{n} \sum_{i=1}^{N} \delta_{n, j} j_{r_{i}} x_{n}, \quad \forall n \geq 1,
$$

where $f$ is an $\alpha$-contraction on $\bigcap_{i=1}^{N} \overline{D\left(A_{i}\right)},\left\{r_{i}\right\}$ be a positive real numbers sequence and $J_{r_{i}}=\left(I+r_{i} A_{i}\right)^{-1}$. Assume that the following conditions are satisfied:

(a) $\alpha_{n}+\beta_{n}+\gamma_{n}=1$

(b) $\lim _{n \rightarrow \infty} \alpha_{n}=0, \sum_{n=1}^{\infty} \alpha_{n}=\infty$;

(c) $0<\liminf _{n \rightarrow \infty} \beta_{n} \leq \limsup _{n \rightarrow \infty} \beta_{n}<1$;

(d) $\sum_{i=1}^{N} \delta_{n, i}=1, \lim _{n \rightarrow \infty} \delta_{n, i}=\delta_{i}$.

Then $\left\{x_{n}\right\}$ converges strongly to $\bar{x}$, which is the unique solution to the following variational inequality: $\left\langle f(\bar{x})-\bar{x}, J_{\varphi}(p-\bar{x})\right\rangle \leq 0, \forall p \in \bigcap_{i=1}^{N} A_{i}^{-1}(0)$.

Proof First, we show that $\left\{x_{n}\right\}$ is bounded. By fixing $p \in \bigcap_{i=1}^{N} A_{i}^{-1}(0)$, we get

$$
\begin{aligned}
\left\|x_{n+1}-p\right\| & \leq \alpha_{n}\left\|f\left(x_{n}\right)-p\right\|+\beta_{n}\left\|x_{n}-p\right\|+\gamma_{n}\left\|\sum_{i=1}^{N} \delta_{n, i} J_{r_{m}} x_{n}-p\right\| \\
& \leq \alpha_{n} \alpha\left\|x_{n}-p\right\|+\alpha_{n}\|f(p)-p\|+\beta_{n}\left\|x_{n}-p\right\|+\gamma_{n} \sum_{i=1}^{N} \delta_{n, i}\left\|J_{r_{i}} x_{n}-p\right\| \\
& \leq\left(1-\alpha_{n}(1-\alpha)\right)\left\|x_{n}-p\right\|+\alpha_{n}(1-\alpha) \frac{\|f(p)-p\|}{1-\alpha} .
\end{aligned}
$$


This implies that

$$
\left\|x_{n+1}-p\right\| \leq \max \left\{\frac{\|f(p)-p\|}{1-\alpha},\left\|x_{1}-p\right\|\right\} .
$$

We find that $\left\{x_{n}\right\}$ is bounded. Putting $y_{n}=\sum_{i=1}^{N} \delta_{n, j} J_{r_{i}} x_{n}$, we see that

$$
\begin{aligned}
\left\|y_{n}-y_{n-1}\right\| \leq & \left\|\sum_{i=1}^{N} \delta_{n, i} J_{r_{i}} x_{n}-\sum_{i=1}^{N} \delta_{n, j} J_{r_{n}} x_{n-1}\right\| \\
& +\left\|\sum_{i=1}^{N} \delta_{n, i} J_{r_{i}} x_{n-1}-\sum_{i=1}^{N} \delta_{n-1, i} J_{r_{i}} x_{n-1}\right\| \\
\leq & \left\|x_{n}-x_{n-1}\right\|+\sum_{i=1}^{N}\left|\delta_{n, i}-\delta_{n-1, i}\right|\left\|J_{r_{i}} x_{n-1}\right\| .
\end{aligned}
$$

Define $z_{n}:=\frac{x_{n+1}-\beta_{n} x_{n}}{1-\beta_{n}}$. This gives

$$
\begin{aligned}
z_{n}-z_{n-1} & =\frac{x_{n+1}-\beta_{n} x_{n}}{1-\beta_{n}}-\frac{x_{n}-\beta_{n-1} x_{n-1}}{1-\beta_{n-1}} \\
& =\frac{\alpha_{n} f\left(x_{n}\right)+\gamma_{n} y_{n}}{1-\beta_{n}}-\frac{\alpha_{n-1} f\left(x_{n-1}\right)+\gamma_{n-1} y_{n-1}}{1-\beta_{n-1}} \\
& =\frac{\alpha_{n}}{1-\beta_{n}}\left(f\left(x_{n}\right)-y_{n}\right)-\frac{\alpha_{n-1}}{1-\beta_{n-1}}\left(f\left(x_{n-1}\right)-y_{n-1}\right)+y_{n}-y_{n-1} .
\end{aligned}
$$

It follows that

$$
\begin{aligned}
\left\|z_{n}-z_{n-1}\right\| \leq & \frac{\alpha_{n}}{1-\beta_{n}}\left\|f\left(x_{n}\right)-y_{n}\right\|+\frac{\alpha_{n-1}}{1-\beta_{n-1}}\left\|f\left(x_{n-1}\right)-y_{n-1}\right\|+\left\|y_{n}-y_{n-1}\right\| \\
\leq & \frac{\alpha_{n}}{1-\beta_{n}}\left\|f\left(x_{n}\right)-y_{n}\right\|+\frac{\alpha_{n-1}}{1-\beta_{n-1}}\left\|f\left(x_{n-1}\right)-y_{n-1}\right\|+\left\|x_{n}-x_{n-1}\right\| \\
& +\sum_{i=1}^{N}\left|\delta_{n, i}-\delta_{n-1, i}\right|\left\|J_{r_{i}} x_{n-1}\right\| .
\end{aligned}
$$

This implies that

$$
\begin{aligned}
\left\|z_{n}-z_{n-1}\right\|-\left\|x_{n}-x_{n-1}\right\| \leq & \frac{\alpha_{n}}{1-\beta_{n}}\left\|f\left(x_{n}\right)-y_{n}\right\|+\frac{\alpha_{n-1}}{1-\beta_{n-1}}\left\|f\left(x_{n-1}\right)-y_{n-1}\right\| \\
& +\sum_{i=1}^{N}\left|\delta_{n, i}-\delta_{n-1, i}\right|\left\|J_{r_{i}} x_{n-1}\right\| .
\end{aligned}
$$

From the conditions (b), (c), and (d), we get

$$
\limsup _{n \rightarrow \infty}\left(\left\|z_{n}-z_{n-1}\right\|-\left\|x_{n}-x_{n-1}\right\|\right) \leq 0
$$

In light of Lemma 1.1, we find that $\lim _{n \rightarrow \infty}\left\|z_{n}-x_{n}\right\|=0$. Since $x_{n+1}-x_{n}=\left(1-\beta_{n}\right)\left(z_{n}-x_{n}\right)$, we have $\lim _{n \rightarrow \infty}\left\|x_{n+1}-x_{n}\right\|=0$. Setting $T=\sum_{i=1}^{N} \delta_{i} J_{r_{i}}$, we from Lemma 1.2 see that $T$ is 
nonexpansive with $F(T)=\bigcap_{i=1}^{N} F\left(J_{r_{i}}\right)=\bigcap_{i=1}^{N} A_{i}^{-1}(0)$. Note that

$$
\begin{aligned}
& \left\|x_{n}-T x_{n}\right\| \\
& \quad \leq\left\|x_{n}-x_{n+1}\right\|+\left\|x_{n+1}-T x_{n}\right\| \\
& \quad \leq\left\|x_{n}-x_{n+1}\right\|+\alpha_{n}\left\|f\left(x_{n}\right)-T x_{n}\right\|+\beta_{n}\left\|x_{n}-T x_{n}\right\|+\gamma_{n}\left\|\sum_{i=1}^{N} \delta_{n, i} J_{r_{i}} x_{n}-T x_{n}\right\| \\
& \quad \leq\left\|x_{n}-x_{n+1}\right\|+\alpha_{n}\left\|f\left(x_{n}\right)-T x_{n}\right\|+\beta_{n}\left\|x_{n}-T x_{n}\right\|+\gamma_{n} \sum_{i=1}^{N}\left|\delta_{n, i}-\delta_{i}\right|\left\|J_{r_{i}} x_{n}\right\| .
\end{aligned}
$$

This implies that

$$
\begin{aligned}
& \left(1-\beta_{n}\right)\left\|x_{n}-T x_{n}\right\| \\
& \quad \leq\left\|x_{n}-x_{n+1}\right\|+\alpha_{n}\left\|f\left(x_{n}\right)-T x_{n}\right\|+\gamma_{n} \sum_{i=1}^{N}\left|\delta_{n, i}-\delta_{i}\right|\left\|J_{r_{i}} x_{n}\right\| .
\end{aligned}
$$

It follows from the conditions (b), (c), and (d) that

$$
\lim _{n \rightarrow \infty}\left\|T x_{n}-x_{n}\right\|=0
$$

Next, we show that $\limsup _{n \rightarrow \infty}\left\langle f(\bar{x})-\bar{x}, J_{\varphi}\left(x_{n}-\bar{x}\right)\right\rangle \leq 0$. Take a subsequence $\left\{x_{n_{j}}\right\}$ of $\left\{x_{n}\right\}$ such that

$$
\limsup _{n \rightarrow \infty}\left\langle f(\bar{x})-\bar{x}, J_{\varphi}\left(x_{n}-\bar{x}\right)\right\rangle=\lim _{j \rightarrow \infty}\left\langle f(\bar{x})-\bar{x}, J_{\varphi}\left(x_{n_{j}}-\bar{x}\right)\right\rangle .
$$

Since $E$ is reflexive, we may further assume that $x_{n_{j}} \rightarrow \hat{x}$ for some $\hat{x} \in \bigcap_{i=1}^{N} \overline{D\left(A_{i}\right)}$. Since $J_{\varphi}$ is weakly continuous, we find from Lemma 1.4 that

$$
\underset{j \rightarrow \infty}{\limsup } \Phi\left(\left\|x_{n_{j}}-x\right\|\right)=\underset{j \rightarrow \infty}{\limsup } \Phi\left(\left\|x_{n_{j}}-\hat{x}\right\|\right)+\Phi(\|x-\hat{x}\|), \quad \forall x \in E .
$$

Putting $f(x)=\limsup _{j \rightarrow \infty} \Phi\left(\left\|x_{n_{j}}-x\right\|\right), \forall x \in E$, we have

$$
f(x)=f(\hat{x})+\Phi(\|x-\hat{x}\|), \quad \forall x \in E
$$

It follows from (2.1) that

$$
\begin{aligned}
f(T \hat{x}) & =\limsup _{j \rightarrow \infty} \Phi\left(\left\|x_{n_{j}}-T \hat{x}\right\|\right) \\
& \leq \limsup _{j \rightarrow \infty} \Phi\left(\left\|T x_{n_{j}}-T \hat{x}\right\|\right) \\
& \leq \limsup _{j \rightarrow \infty} \Phi\left(\left\|x_{n_{j}}-\hat{x}\right\|\right)=f(\bar{x}) .
\end{aligned}
$$

On the other hand, we find from (2.3) that

$$
f(T \hat{x})=f(\hat{x})+\Phi(\|T \hat{x}-\hat{x}\|) .
$$


In view of (2.4) and (2.5), we find that $\Phi(\|T \hat{x}-\hat{x}\|) \leq 0$. This implies that $T \hat{x}=\hat{x}$; that is, $\hat{x} \in F(T)=\bigcap_{i=1}^{N} A_{i}^{-1}(0)$. In light of (2.2), we find that

$$
\limsup _{n \rightarrow \infty}\left\langle f(\bar{x})-\bar{x}, J_{\varphi}\left(x_{n}-\bar{x}\right)\right\rangle \leq 0
$$

Now, we are in a position to prove $x_{n} \rightarrow \bar{x}$ as $n \rightarrow \infty$. Using Lemma 1.1, we find that

$$
\begin{aligned}
\Phi\left(\left\|x_{n+1}-\bar{x}\right\|\right)= & \Phi\left(\| \alpha_{n}\left(f\left(x_{n}\right)-f(\bar{x})\right)+\alpha_{n}(f(\bar{x})-\bar{x})+\beta_{n}\left(x_{n}-\bar{x}\right)\right. \\
& \left.+\gamma_{n}\left(\sum_{i=1}^{N} \beta_{n, i} J_{r_{i}} x_{n}-\bar{x}\right) \|\right) \\
\leq & \Phi\left(\left\|\alpha_{n}\left(f\left(x_{n}\right)-f(\bar{x})\right)+\beta_{n}\left(x_{n}-\bar{x}\right)+\gamma_{n}\left(\sum_{i=1}^{N} \beta_{n, i} J_{r_{i}} x_{n}-\bar{x}\right)\right\|\right) \\
& +\alpha_{n}\left\langle f(\bar{x})-\bar{x}, J_{\varphi}\left(x_{n+1}-\bar{x}\right)\right\rangle \\
\leq & \left(1-\alpha_{n}(1-\alpha)\right) \Phi\left(\left\|x_{n}-\bar{x}\right\|\right)+\alpha_{n}\left\langle f(\bar{x})-\bar{x}, J_{\varphi}\left(x_{n+1}-\bar{x}\right)\right\rangle .
\end{aligned}
$$

It follows from Lemma 1.5 that $\Phi\left(\left\|x_{n}-\bar{x}\right\|\right) \rightarrow 0$. This implies that $\lim _{n \rightarrow \infty}\left\|x_{n}-\bar{x}\right\|=0$. This completes the proof.

If $A_{1}=A_{2}=\cdots=A_{N}$, the restriction of strict convexness imposed on the framework of the space can be removed. Indeed, we have the following result.

Corollary 2.2 Let E be a reflexive Banach space which has a weakly continuous duality map $J_{\varphi}$. Let $A$ be an m-accretive operator in $E$ such that $\overline{D(A)}$ is convex and $A^{-1}(0)$ is not empty. Let $\left\{\alpha_{n}\right\},\left\{\beta_{n}\right\}$ and $\left\{\gamma_{n}\right\}$ be real number sequences in $(0,1)$. Let $\left\{x_{n}\right\}$ be a sequence in $\overline{D(A)}$ generated in the following iterative process: $x_{1} \in \overline{D(A)}$ and

$$
x_{n+1}=\alpha_{n} f\left(x_{n}\right)+\beta_{n} x_{n}+\gamma_{n} J_{r} x_{n}, \quad \forall n \geq 1,
$$

wheref is an $\alpha$-contraction on $\overline{D\left(A_{i}\right)}$, r be a positive real number and $J_{r}=(I+r A)^{-1}$. Assume that the following conditions are satisfied:

(a) $\alpha_{n}+\beta_{n}+\gamma_{n}=1$

(b) $\lim _{n \rightarrow \infty} \alpha_{n}=0, \sum_{n=1}^{\infty} \alpha_{n}=\infty$;

(c) $0<\liminf _{n \rightarrow \infty} \beta_{n} \leq \limsup _{n \rightarrow \infty} \beta_{n}<1$.

Then $\left\{x_{n}\right\}$ converges strongly to $\bar{x}$, which is the unique solution to the following variational inequality: $\left\langle f(\bar{x})-\bar{x}, J_{\varphi}(p-\bar{x})\right\rangle \leq 0, \forall p \in A^{-1}(0)$.

In the framework of Hilbert spaces, we find from Theorem 2.1 the following result.

Corollary 2.3 Let $E$ be a Hilbert space. Let $N \geq 1$ be some positive integer and let $A_{i}$ be a maximal monotone operator in $E$ for each $i \in\{1,2, \ldots, N\}$. Assume that $\bigcap_{i=1}^{N} \overline{D\left(A_{i}\right)}$ is convex and $\bigcap_{i=1}^{N} A_{i}^{-1}(0)$ is not empty. Let $\left\{\alpha_{n}\right\},\left\{\beta_{n}\right\},\left\{\gamma_{n}\right\}$ and $\left\{\delta_{n, i}\right\}$ be real number sequences in $(0,1)$. Let $\left\{x_{n}\right\}$ be a sequence in $\bigcap_{i=1}^{N} \overline{D\left(A_{i}\right)}$ generated in the following iterative process: 
$x_{1} \in \bigcap_{i=1}^{N} \overline{D\left(A_{i}\right)}$ and

$$
x_{n+1}=\alpha_{n} f\left(x_{n}\right)+\beta_{n} x_{n}+\gamma_{n} \sum_{i=1}^{N} \delta_{n, i} J_{r_{i}} x_{n}, \quad \forall n \geq 1,
$$

where $f$ is an $\alpha$-contraction on $\bigcap_{i=1}^{N} \overline{D\left(A_{i}\right)},\left\{r_{i}\right\}$ be a positive real numbers sequence and $J_{r_{i}}=\left(I+r_{i} A_{i}\right)^{-1}$. Assume that the following conditions are satisfied:

(a) $\alpha_{n}+\beta_{n}+\gamma_{n}=1$

(b) $\lim _{n \rightarrow \infty} \alpha_{n}=0, \sum_{n=1}^{\infty} \alpha_{n}=\infty$;

(c) $0<\liminf _{n \rightarrow \infty} \beta_{n} \leq \limsup _{n \rightarrow \infty} \beta_{n}<1$;

(d) $\sum_{i=1}^{N} \delta_{n, i}=1, \lim _{n \rightarrow \infty} \delta_{n, i}=\delta_{i}$

Then $\left\{x_{n}\right\}$ converges strongly to $\bar{x}$, which is the unique solution to the following variational inequality: $\langle f(\bar{x})-\bar{x}, p-\bar{x}\rangle \leq 0, \forall p \in \bigcap_{i=1}^{N} A_{i}^{-1}(0)$.

\section{Competing interests}

The authors declare that they have no competing interests.

\section{Authors' contributions}

Both authors contributed equally and significantly in writing this paper.

\section{Author details}

${ }^{1}$ Department of Mathematics, Hangzhou Normal University, Hangzhou, Zhejiang, China. ${ }^{2}$ School of Mathematics and Information Science, Shangqiu Normal University, Shangqiu, Henan, China.

\section{Acknowledgements}

The authors are grateful to the reviewers for valuable suggestions which significantly improved the contents of the work.

\section{Received: 14 March 2014 Accepted: 7 May 2014 Published: 20 May 2014}

\section{References}

1. Browder, FE: Nonlinear mappings of nonexpansive and accretive type in Banach spaces. Bull. Am. Math. Soc. 73, 875-882 (1967)

2. Kamimura, S, Takahashi, W: Weak and strong convergence of solutions to accretive operator inclusions and applications. Set-Valued Anal. 8, 361-374 (2000)

3. Qin, X, Cho, SY, Wang, L: A regularization method for treating zero points of the sum of two monotone operators. Fixed Point Theory Appl. 2014, Article ID 75 (2014)

4. Rockfellar, RT: Monotone operators and proximal point algorithm. SIAM J. Control Optim. 14, 877-898 (1976)

5. Qin, X, Su, Y: Approximation of a zero point of accretive operator in Banach spaces. J. Math. Anal. Appl. 329, 415-424 (2007)

6. Cho, SY, Qin, X, Wang, L: Strong convergence of a splitting algorithm for treating monotone operators. Fixed Point Theory Appl. 2014, Article ID 94 (2014)

7. Lv, S: Generalized systems of variational inclusions involving $(A, \eta)$-monotone mappings. Adv. Fixed Point Theory 1 , 15-26 (2011)

8. Wu, C, Lv, S: Bregman projection methods for zeros of monotone operators. J. Fixed Point Theory 2013, Article ID 7 (2013)

9. Wu, C: Convergence of algorithms for an infinite family nonexpansive mappings and relaxed cocoercive mappings in Hilbert spaces. Adv. Fixed Point Theory 4, 125-139 (2014)

10. Cho, SY, Li, W, Kang, SM: Convergence analysis of an iterative algorithm for monotone operators. J. Inequal. Appl. 2013, Article ID 199 (2013)

11. Wang, ZM, Lou, W: A new iterative algorithm of common solutions to quasi-variational inclusion and fixed point problems. J. Math. Comput. Sci. 3, 57-72 (2013)

12. Qing, Y, Cho, SY: Proximal point algorithms for zero points of nonlinear operators. Fixed Point Theory Appl. 2014, Article ID 42 (2014)

13. Yang, S: Zero theorems of accretive operators in reflexive Banach spaces. J. Nonlinear Funct. Anal. 2013, Article ID 2 (2013)

14. Song, J, Chen, M: A modified Mann iteration for zero points of accretive operators. Fixed Point Theory Appl. 2013, Article ID 347 (2013)

15. Qin, $X$, Cho, SY, Wang, L: Iterative algorithms with errors for zero points of $m$-accretive operators. Fixed Point Theory Appl. 2013, Article ID 148 (2013)

16. Takahashi, W: Viscosity approximation methods for resolvents of accretive operators in Banach spaces. J. Fixed Point Theory Appl. 1, 135-147 (2007) 
17. Reich, S: Strong convergence theorems for resolvents of accretive operators in Banach spaces. J. Math. Anal. Appl. 75, 287-292 (1980)

18. Bauschke, HH, Matousková, E, Reich, S: Projection and proximal point methods: convergence results and counterexamples. Nonlinear Anal. 56, 715-738 (2004)

19. Cho, SY, Qin, X: On the strong convergence of an iterative process for asymptotically strict pseudocontractions and equilibrium problems. Appl. Math. Comput. 235, 430-438 (2014)

20. Jung, JS: Some results on Rockafellar-type iterative algorithms for zeros of accretive operators. J. Inequal. Appl. 2013, Article ID 255 (2013)

21. Qin, X, Agarwal, RP: Shrinking projection methods for a pair of asymptotically quasi- $\boldsymbol{\phi}$-nonexpansive mappings Numer. Funct. Anal. Optim. 31, 1072-1089 (2010)

22. Takahashi, W: Approximating solutions of accretive operators by viscosity approximation methods in Banach spaces. In: Applied Functional Analysis, pp. 225-243. Yokohama Publishers, Yokohama (2007)

23. Verma, RU: General proximal point algorithm involving $\eta$-maximal accretiveness framework in Banach spaces. Positivity 13, 771-782 (2009)

24. Cho, SY, Kang, SM: Approximation of common solutions of variational inequalities via strict pseudocontractions. Acta Math. Sci. 32, 1607-1618 (2012)

25. Li, HG, Qiu, D, Zheng, JM, Jin, MM: Perturbed Ishikawa-hybrid quasi-proximal point algorithm with accretive mappings for a fuzzy system. Fixed Point Theory Appl. 2013, Article ID 281 (2013)

26. Plubtieng, S, Sriprad, W: An extragradient method and proximal point algorithm for inverse strongly monotone operators and maximal monotone operators in Banach spaces. Fixed Point Theory Appl. 2009, Article ID 591874 (2009)

27. Cho, SY: Iterative processes for common fixed points of two different families of mappings with applications. J. Glob. Optim. 57, 1429-1446 (2013)

28. Browder, FE: Convergence theorems for sequences of nonlinear operators in Banach spaces. Math. Z. 100, 201-225 (1967)

29. Qin, X, Su, Y: Strong convergence theorems for relatively nonexpansive mappings in a Banach space. Nonlinear Anal. TMA 67, 1958-1965 (2007)

30. Krasnosel'skii, MA, Zabreiko, PP: Geometrical Metods for Nonlinear Analysis. Springer, New York (1984)

31. Zeidler, E: Nonlinear Functional Analysis and Its Applications. I. Fixed-Point Theorems. Springer, New York (1986)

32. Qin, X, Cho, YJ, Kang, SM: Convergence theorems of common elements for equilibrium problems and fixed point problems in Banach spaces. J. Comput. Appl. Math. 225, 20-30 (2009)

33. Tseng, P: Applications of a splitting algorithm to decomposition in convex programming and variational inequalities. SIAM J. Control Optim. 29, 119-138 (1991)

34. Mouallif, K, Nguyen, VH, Strodiot, J-J: A perturbed parallel decomposition method for a class of nonsmooth convex minimization problems. SIAM J. Control Optim. 29, 829-847 (1991)

35. Cho, SY, Kang, SM: Hybrid projection algorithms for treating common fixed points of a family of demicontinuous pseudocontractions. Appl. Math. Lett. 25, 854-857 (2012)

36. Lim, TC, Xu, HK: Fixed point theorems for asymptotically nonexpansive mappings. Nonlinear Anal. 22, 1345-1355 (1994)

37. Bruck, RE: Properties of fixed-point sets of nonexpansive mappings in Banach spaces. Trans. Am. Math. Soc. 179 251-262 (1973)

38. Xu, HK: Strong convergence of an iterative method for nonexpansive and accretive operators. J. Math. Anal. Appl. 314, 631-643 (2006)

39. Suzuki, T: Strong convergence of Krasnoselskii and Mann's type sequences for one-parameter nonexpansive semigroups without Bochner integrals. J. Math. Anal. Appl. 305, 227-239 (2005)

40. Liu, LS: Ishikawa and Mann iterative process with errors for nonlinear strongly accretive mappings in Banach spaces. J. Math. Anal. Appl. 194, 114-125 (1995)

10.1186/1687-1812-2014-125

Cite this article as: Qing and Lv: Strong convergence of a parallel iterative algorithm in a reflexive Banach space. Fixed Point Theory and Applications 2014, 2014:125

\section{Submit your manuscript to a SpringerOpen ${ }^{\circ}$ journal and benefit from:}

- Convenient online submission

- Rigorous peer review

- Immediate publication on acceptance

- Open access: articles freely available online

- High visibility within the field

- Retaining the copyright to your article 